\title{
Metastatic Disease in the Stomach
}

\author{
Jochen Weigt Peter Malfertheiner \\ Department of Gastroenterology, Hepatology and Infectious Diseases, Otto von Guericke \\ University of Magdeburg, Magdeburg, Germany
}

\author{
Key Words \\ Endoscopic diagnosis · Gastric metastasis · Metastases · Stomach
}

\begin{abstract}
Background: Gastric metastases are rare and represent a late and progressed stage of malignant disease. This review highlights epidemiological, clinical and endoscopic findings as well as therapeutic strategies for metastatic disease of the stomach. Summary: The clinical presentation of gastric metastases is highly unspecific. The endoscopic appearance of gastric metastases is heterogeneous, but the most prevalent findings are solitary and submucosal lesions in the gastric wall. The most prevalent primary tumor spreading to the stomach is breast cancer, followed by renal cell cancer and many others. In general, gastric metastases occur in a late stage of malignant disease and frequently indicate short survival. Specific therapy for gastric metastases does not exist and is mainly performed with chemotherapy according to the primary tumor. Compared with other metastatic diseases, gastric metastases of renal cell cancer and breast cancer need distinct consideration. Gastric metastasis of these cancers presents with a better prognosis, as patients with these conditions can be offered effective chemotherapeutic treatment. Key Message: Gastric metastatic disease is a rare clinical presentation. The pathophysiology of gastric metastatic seeding is not well understood. Practical Implications: In the course of malignant disease the presence of gastric metastases should be taken into account if mucosal or submucosal gastric lesions are present. Therapy in general depends on the primary tumor.

(c) 2015 S. Karger AG, Basel
\end{abstract}

\section{Introduction}

Metastatic disease of cancerous lesions mostly spreads by lymphatic drainage and blood supply. Accordingly some organs are much more predisposed targets of metastasis than others. This is the case for the liver, lung and locoregional lymph nodes, according to the type and location of the primary tumor. In general, metastases can develop at every site of the 
body, but usually distant metastases occur more frequently in late disseminated stages of cancer. The stomach itself is frequently the source of metastatic disease, mostly through advanced gastric cancer, but may also harbor metastasis of other malignancies. This short review reports key findings of metastatic disease in the stomach.

\section{Frequency}

Metastases in the stomach are an infrequent finding. The incidence in clinical and autopsy series is reported to vary between 0.2 and $0.7 \%[1,2]$. Reports available in the literature are mostly related to case presentations or small case series. This leaves unsolved questions concerning the underlying pathophysiological condition and the molecular mechanisms of gastric metastases. Hematogenous dissemination, peritoneal dissemination, lymphatic infiltration or direct invasion are routes of gastric metastases.

Among primary tumor entities spreading to the stomach, a high prevalence of breast cancer (27\%), lung cancer (23\%), renal cell cancer (7.6\%) and malignant melanoma (7\%) has been reported [3]. Furthermore infiltrations of lymphoma and leukemia in the stomach may occur [3].

\section{Endoscopic Findings}

In malignant melanoma it is a usual finding that the mucosa presents with brownish or black flat or elevated areas or lesions [4, 5]. However, metastases of amelanotic melanoma are usually unpigmented, and amelanotic metastases of primary melanotic melanoma have been described in the stomach as well [6].

A recent report on 37 patients with gastric metastases of solid organs described that metastases most frequently present with submucosa-type lesions (fig. 1) and that solitary lesions are more frequent than multiple lesions [7] (fig. 2). Lesions can also appear as polypoid masses [8], ulcers [4] or ulcerated protruding lesions [7, 9]. There is no typical pit pattern as in the endoscopic classification systems of gastric cancer, which would allow to clearly identify a gastric lesion as a metastasis. This highlights the need for adequate biopsy sampling in order to confirm the exact nature of unclear gastric mucosal lesions [10].

\section{Clinical Presentation}

A review by Namikawa and Hanazaki [3] demonstrated that the average age of patients with gastric metastases as reported in the literature is 59.1 years, ranging from 56 to 71 years, and that the average time between primary diagnosis of malignancy and gastric metastases is 16-78 months. Interestingly, gastric metastases of breast cancer and renal cell cancer occur with greater delay from the initial tumor diagnosis (75.6 and 50-78 months, respectively).

The clinical presentation of gastric metastases is not typical. Symptoms reported are epigastric pain, dysphagia and vomiting [7]. A considerable number of patients are identified with gastrointestinal hemorrhage $[7,11]$ and others by chance during staging endoscopies that are performed in the context of a known primary or even in search of a primary tumor.

The survival time after detection of gastric metastases is short and was 3 months in median, ranging from 1 to 11 months in a series of 37 cases. Patients with a solitary metastasis had longer survival than patients with multiple gastric metastases [7]. However, survival mainly depends on the type and stage of the primary tumor. 


\section{Gastro \\ Intestinal \\ Tumors}

Fig. 1. Endosonographic appearance of a submucosal gastric metastasis of a papillary ovarian cancer. The metastasis was located in the outer layers of the stomach. Endoscopy revealed a bulging in the corpus of the stomach without any visible mucosal lesion. The primary tumor had been diagnosed 7 months earlier.

Fig. 2. Gastric metastasis of a renal cell cancer appearing 2 years after right-sided renal resection. Multiple metastatic lesions can be seen in the corpus.

\begin{tabular}{l|l}
\hline Gastrointest Tumors 2015;2:61-64 \\
\hline DOI: 10.1159/000431304 & $\begin{array}{l}\text { @ 2015 S. Karger AG, Basel } \\
\text { www.karger.com/gat }\end{array}$ \\
\hline
\end{tabular}

Weigt and Malfertheiner: Metastatic Disease in the Stomach
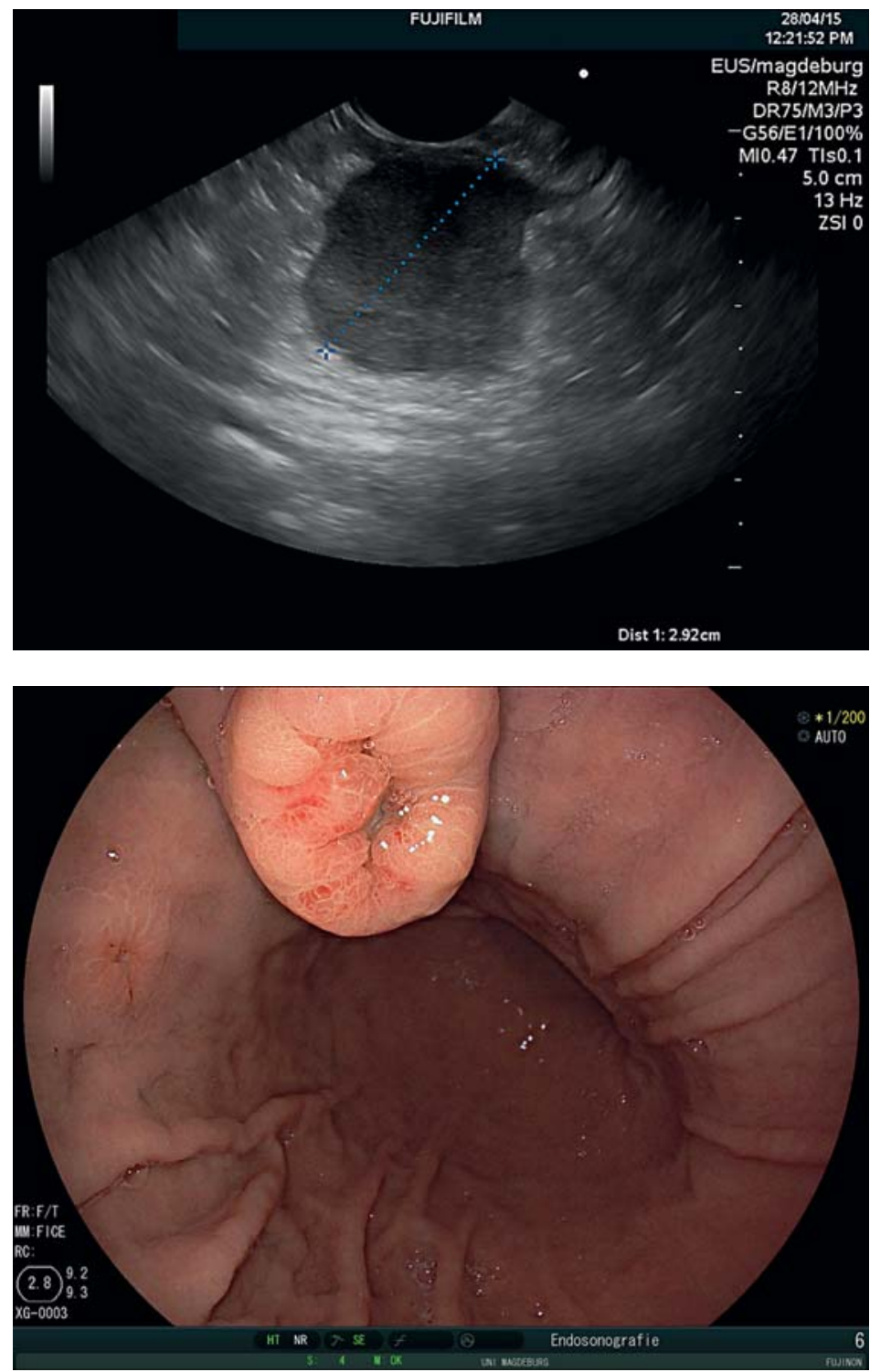

Attention should be paid to late-onset gastric metastases that can develop even years after the initial diagnosis of a malignant disease. Onorati et al. [12] presented a case of gastric metastasis 20 years after renal cell carcinoma. Sofos et al. [13] described a gastric metastasis from uveal melanoma 12 years after initial diagnosis, and Mehrzad et al. [14] described a late prostate cancer metastasis with a latency of 9 years.

\section{Therapy}

Gastric metastases are mostly singular but can be disseminated over the stomach, as in the case of malignant melanoma. Since gastric metastases appear in the late stage of a malignant disease, the therapy generally consists of systemic chemotherapy for the primary tumor rather than surgery. Local complications such as obstruction or bleeding are treated by endoscopy or surgery [15] with palliative intention. Standard endoscopic hemostatic 
procedures or stents are treatment methods of choice. Gastric surgery should be considered in tumor entities that may require metastatic surgery to improve outcome, such as renal cancer and colon cancer. The indication for surgery is the proof that the gastric metastasis is solitary, and thus careful diagnostic workup is warranted.

Because of targeted chemotherapy regimens for renal cell cancer and breast cancer the survival in these patients with gastric metastases is longer compared to other primary tumors [3].

\section{Conclusion}

The presentation of gastric metastases is rare and the mechanisms of metastatic disease in the stomach are not clear. Gastric metastatic disease is generally a sign of late stage of a malignant disease. The treatment of gastric metastases in most cases is driven by the primary malignancy and mainly based on chemotherapy. The prognosis is determined by the primary tumor site. Clinical presentation is highly unspecific and endoscopic appearance is heterogeneous. Therefore gastric metastases have to be taken into account as a differential diagnosis for gastric lesions and need careful workup.

\section{Disclosure Statement}

Jochen Weigt and Peter Malfertheiner declare no conflict of interest related to this paper.

\section{References}

1 De Palma GD, Masone S, Rega M, Simeoli I, Donisi M, Addeo P, Iannone L, Pilone V, Persico G: Metastatic tumors to the stomach: clinical and endoscopic features. World J Gastroenterol 2006;12:7326-7328.

2 Kobayashi O, Murakami H, Yoshida T, Cho H, Yoshikawa T, Tsuburaya A, Sairenji M, Motohashi H, Sugiyama Y, Kameda Y: Clinical diagnosis of metastatic gastric tumors: clinicopathologic findings and prognosis of nine patients in a single cancer center. World J Surg 2004;28:548-551.

-3 Namikawa T, Hanazaki K: Clinicopathological features and treatment outcomes of metastatic tumors in the stomach. Surg Today 2014;44:1392-1399.

4 Eivazi-Ziaei J, Esmaili H: Metastatic malignant melanoma affecting stomach. J Cancer Res Ther 2014;10:733-736

5 Rana SS, Chaudhary V, Bhasin DK: Narrow band imaging appearance of gastric metastasis from malignant melanoma. Ann Gastroenterol 2013;26:353.

-6 Ozturk 0, Basar 0, Koklu S, Yuksel O, Purnak T, Sokmensuer C: An unusual presentation of malignant melanoma: amelanotic gastric metastasis. Am J Gastroenterol 2015;110:476.

7 Kim GH, Ahn JY, Jung HY, Park YS, Kim MJ, Choi KD, Lee JH, Choi KS, Kim DH, Lim H, Song HJ, Lee GH, Kim JH: Clinical and endoscopic features of metastatic tumors in the stomach. Gut Liver 2014, Epub ahead of print.

-8 Kumcu E, Gonultas M, Unverdi H, Hucumenoglu S: Gastric metastasis of a renal cell carcinoma presenting as a polypoid mass. Endoscopy 2014;46(suppl 1 UCTN):E464.

-9 Shaaban H, Modi Y, Modi T, Guron G: Diffuse gastroduodenal metastasis from cutaneous malignant melanoma presenting as amelanotic 'volcano-like' ulcers. J Gastrointest Cancer 2014;45:116-117.

10 Oda I, Kondo H, Yamao T, Saito D, Ono H, Gotoda T, Yamaguchi H, Yoshida S, Shimoda T: Metastatic tumors to the stomach: analysis of 54 patients diagnosed at endoscopy and 347 autopsy cases. Endoscopy 2001;33:507-510.

-11 Sakurai K, Muguruma K, Yamazoe S, Kimura K, Toyokawa T, Amano R, Kubo N, Tanaka H, Yashiro M, Ohira M, Hirakawa K: Gastric metastasis from renal cell carcinoma with gastrointestinal bleeding: a case report and review of the literature. Int Surg 2014;99:86-90.

-12 Onorati M, Petracco G, Uboldi P, Redaelli DG, Romagnoli S, Albertoni M, Di Nuovo F: A solitary polypoid gastric metastasis 20 years after renal cell carcinoma: an event to be considered, and a brief review of the literature. Pathologica 2013;105:132-136.

13 Sofos S, Azagra JS, Arru L, Ries F, Leider P, Weber J, Goergen M: Multidisciplinary management of a gastric metastasis of uveal melanoma presenting 12 years after enucleation. Bull Soc Sci Med Grand Duche Luxemb 2013;2: 63-68.

14 Mehrzad R, Agarwal A, Faller GT, Fiore JA: Prostate cancer metastasis to the stomach: 9 years after the initial diagnosis - case report and a literature review. J Gastrointest Cancer 2014;45(suppl 1):40-43.

15 Kim YI, Kang BC, Sung SH: Surgically resected gastric metastasis of pulmonary squamous cell carcinoma. World J Gastrointest Surg 2013;5:278-281. 